\title{
ProfeSSiONALISED INTIMACY: How Dementia Care Workers Navigate BetWeen DOMESTIC INTIMACY AND INSTITUTIONAL DETACHMENT
}

\begin{abstract}
This paper reports an ethnographic study of the handover routines in Germany's first Dementia Village, with a central focus on how care is balanced between domestic intimacy and institutional detachment. The term 'professionalised intimacy' is used for the vivid interplay between comfort and intimacy that renders the interaction between care workers and residents far more complex than previous theories have articulated. Because of the intimacy involved in community building, however, the promise of personalised care must clash with the bureaucratic structures of an official institution, potentially depriving the care workers of their public, respected identity in the process. The study further suggests that most care workers, in fact, support this division between domestic intimacy and institutional detachment. Even if they subscribe to a dementia village's philosophy of personalised care, their medical training and enculturation has endowed them with a habitus compatible with the modern health profession, with incentives on achieving quantifiable health goals. The dementia village is thus illustrated as a pioneering health care experiment that negotiates rivalling discourses of intimacy, professionalisation, and medicalisation.
\end{abstract}

\section{INTRODUCTION: THE DeMENTIA ViLlage}

In the early 1970s, sociologist Irving Zola (1972) invented the term "medicalisation” to describe the medical jurisdiction's propensity to enclose ever-broader sections of the human experience. Classical medicalisation theory thereafter tended to focus on hierarchy, social control, deviant behaviour, as well as the 
characterisations and definitions of pathology (Bell 1987; Turner 1995; Conrad 1992; 2007; Foucault 2000; Nye 2003), and for decades medical care has been critiqued as a method of social control (e.g. Goffman 1961; Foucault 1989 [1963]; Zola 1972). The 1960s, in particular, were a time of unprecedented societal change. Burgeoning liberal views and policies, and flaws becoming apparent in the welfare structures, have prompted long-term institutional care to be increasingly scrutinised. As a result, countries have devised a variety of innovative forms of housing such as assisted living communities, with the aim of reinforcing civic engagement and allowing people to live in their familiar surroundings for as long as possible.

In response to these developments, a new model of a dementia village was developed in the Netherlands: the Hogewey nursing home. It offered a new model for dementia care in a community setting without the hospital façade. Branded as an innovative, humane, and affordable model of dementia care, the village today hosts around 150 residents, averaging 83 years of age. Roughly 250 full- and part-time health care workers and local volunteers care for the residents. The residents live in 23 different homes, each catering for six or seven residents. These are categorised in seven diverse 'lifestyle categories', which entail housing for the Dutch upper class, homemakers, trade/craftsmen and women, as well as religious, cultured, Indonesian (for those who most value their ethnic heritage) or urban residents.

Two core principles govern the village. First, residents are surrounded by familiar kinds of objects and people with similar values, backgrounds and interests to create experiences that echo the resident's formative years. Second, much emphasis is placed on keeping the residents active and in a safe environment (Hurley 2012; Berry 2013). Upon its opening in 2009, scores of journalists flocked to the small Amsterdam suburb. With enthusiasm and assured clarity, they proclaimed that a new care approach for one of the least understood and most frightening plagues of our society had finally arrived. ${ }^{1}$ In brief, the care village seemed to allow people with dementia to live an ordinary life post-dementia diagnosis, when we would usually no longer expect those lives to be ordinary. The dementia village's success appeared to lie in the fact that it did not overly concern itself with illness. Instead, it focused on people. Due to Hogewey's popularity and commercial value, I chose to conduct my research in another dementia village that had been inspired by its

\footnotetext{
${ }^{1}$ See also Grün 1998; Hogewoning-van der Vossen 2004; Hurley 2012; Berry 2013; or Jenkins and Smythe 2013.
} 
Dutch counterpart: Tönebön am See; Germany's first dementia village. ${ }^{2}$ In this paper I report on a particular strand of an ethnographic study which details a still an emerging model of care and support to people living with dementia: the care village. Carol McAllister and Myrna Silverman's (1999: 82) work on the process of community formation and the maintenance of community roles in dementia care settings is relevant in this context. Their comparative study of a residential Alzheimer's facility and a traditional nursing home demonstrates that despite the differences in setting and population the development of community is not only fostered by a shared common territory, but, equally important, by 'the presence of forms of social organization that promote social interactions and relationships'. These forms of social organisation included two particularly important additional features, namely the engagement of the residents with dementia with other residents as well as opportunities to take part in ceremonial activities. Another notable study is Lisa Groger's (1995: 151) interview-based work exploring the long-term care choices of 20 African-American elders. Her analysis suggests that 'nursing home residents indeed can establish 'a sense of satisfying connections between self and environment akin to feeling at home'.

At the heart of this study is the depiction of the fluid structure and identity of the evolving care village model itself. The data excerpts reflect the tensions that frame the emerging village model and trace a slow shift in care culture as medicalised surveillance and discourses of professionalization impact on the daily workings of the facility. This, I will argue, represents a shift away from the ideals, values and principles upon which the village was originally conceived. There is a rich vein of ethnographic research in care home settings which has sought to interrogate the rigid and routinized patterns of care and their implications for the experience of both staff and residents. The article continues this path, carved by many social scientists who have likewise adopted a qualitative approach to add more nuance and complexity to the geriatric care discourse. With his landmark study 'Living and Dying at Murray Manor’, Jaber Gubrium (1975), for instance, methodically documents how the staff, relatives, visiting physicians, and funeral directors accomplish the 'work' of everyday life in a nursing home. Besides introducing useful phrases such as 'bed and body work' to discuss the resident's loss of individuality, Gubrium demonstrates how ethnographic techniques have gained a wider currency in the study of ageing. In his later work, Gubrium (1993) extends his exploration

\footnotetext{
${ }^{2}$ For a more elaborate account of the philosophy, values, principles and setup of Germany's first Dementia Village, as expressed by the village developers and stakeholders see Haeusermann $2017 \mathrm{~b}$.
} 
of long-term geriatric care by organising and interpreting the residents' experiences inside and outside the nursing home ('narrative linkages') and when they speak of life ('horizons of meaning'). Timothy Diamond (1986), on the other hand, places his first hand reports on geriatric care work within the context of wider political, economic, and cultural forces. Shedding light on the 'invisibilities of caring work' and the 'passification process of patient life'. In 'Making Grey Gold' (1992), he then vividly documents the commodification of long-term care.

This article is thus situated at a particularly ambiguous juncture in the study of medicalisation, at the intersection of bureaucratisation and deprofessionalisation. It speaks to the labour of care and the often disorientating nature of the intimacy involved in dementia care work and builds on the work of other scholars who have likewise identified an interplay between comfort and intimacy that renders the interaction between care workers and residents far more complex than prior theories have articulated (also see Farmer 1996 Lopez 2006; Harnett 2010; Pols 2012).

\section{METHODOLOGY}

The village had opened its doors in March 2014 on the southern outskirts of Hamelin, modelled after the Dutch dementia village. This led to four houses, all decorated in different colours and themes, offering space for 52 residents in total. Upon hearing about the village's opening, I established contact with the home's manager and asked for permission to conduct participant observation, which I was granted. ${ }^{3}$ This allowed me to follow the development of the project during its first year as a fledgling operation. The setting provided invaluable insights into the various trials and tribulations of community creation within the confines of the modern welfare state. Between May and December 2014, I thus conducted ethnographic research in the village. This involved a four-month period of intensive study, during which I lived in Hamelin. Initially, the care staff comprised 18 team members ( 15 women, 3 men). 27 residents had already moved in, with more moving in every day. I spent nearly every day at the village, observing the typical daily activities and assisting the care workers in their care routine. In August of that year, I accompanied the night

\footnotetext{
3 As is standard procedure at the University of Cambridge, the initial approval to conduct my study was previously granted by the departmental ethics review. Besides the manager, the head nurse and the foundation council of Tönebön am See and the Tönebön Foundation also gave their approval. .
} 
shift workers for one month in order to gain insight into the village's night-time care activities. In total, I observed approximately 650 hours of care work, which entailed countless conversations with care workers, residents, and administrators. I further attended around 60 handover meetings. I joined the handover meetings, mostly sitting quietly in the back, though sometimes contributing to discussions. In order to most accurately represent the discussions and observations during handover meetings, I sometimes asked if I could record the meetings in order for me to transcribe them later.

Upon translating and arranging all my notes, I rephrased and reconstructed the narratives into more refined and polished ethnographic texts. As Michael Huberman and Matthew Miles (1994) illustrate, this process can be seen as both the selection and condensation of data. Given that I aimed to develop subject-related theories (grounded theory), I developed my own codes inductively. In doing so, the initial coding of all transcripts and notes happened without preconceived notions in mind (open coding). This required me asking myself the rather fundamental questions: 'What is this data a study of?', 'what category does this incident indicate?', and 'what is actually happening in the data?' (Thornberg and Charmaz 2014: 156). Throughout this process, I wrote up theorising ideas about the codes and their relationships (memoing), which, in a later step helped me conceptualising how the different codes relate to one another (theoretical coding). Initially, countless themes emerged and I went on to consider them provisionally. I had gathered data on normality, exclusion, the borders of freedom, the many residents without memory problems, and the care workers who had left the project. I then confirmed whether they were repeatedly present in my notes (also see Corbin and Strauss 1990: 7). Many themes I discounted; some remained. Although I had initially been interested in ideas of selfhood and autonomy, my fieldnotes did not yield many insights into these concepts. Rather, professionalism and intimacy, as well as continuity and change, crept up again and again, in talks, descriptions, and transcripts. These concepts I then employed to code my notes (closed thematic coding). Hence, while significant parts of my study took into account the lives and experiences of the residents, in this paper I take a closer look at the care workers and how, during handover procedures, they commonly negotiated between the personal and the administrative or between empathy and professionalism. 


\section{THE HANDOVER}

In the dementia village, the care workers interacted with the residents. They worked for them but did not live with them. And besides the care worker-resident relationship, various administrative tasks filled the care workers' workday. This day was divided into three shifts: a day shift, the afternoon shift, and the night shift. ${ }^{4}$ When the shifts changed ${ }^{5}$, the teams held a handover meeting: a process of information transfer as well as a transfer of professional responsibility and accountability. Here, the care workers discussed the day's events and, accordingly, enabled the arriving shift to grasp the problems of the prior shift. Ideally, the information was relevant, accurate, unambiguous, and given in a timely manner. By and large, the care workers began by briefly describing the extent to which they implemented emotional and interactional interventions during their shift. They then touched on related changes based on personal observation. Later on, the charge nurse discussed pertinent events from the resident logs, any new issues requiring attention, and any suggested modifications to the care plan for the team's consideration. Besides these technical functions, the handover was also the one time in the day when all the care workers sat together in a room. It provided a place for care workers to address interpersonal conflicts and to voice discontent. As such, it was equally a space for care workers to vent and work through frustrations and anxieties. As the end of a shift approached, the care workers began moving from the village's various buildings and rooms to the care office termed the 'pool' at the heart of which were two desks with two large computer monitors. Here is an example of an evening handover at the home:

In summer, I had accompanied the night shift workers for over a month, so by now the handover routine is familiar to me. Having spent several months in their company, I know the care workers well and they speak freely and openly when I am around. I returned in December to see how the project was evolving. It is a week before Christmas and it is nearly $9.30 \mathrm{pm}$. I enter the 'pool' and find a space to sit. The day care workers have already left. They were exhausted and the charge nurse told them to go home and recover. Many residents are writhing in the grips

\footnotetext{
${ }^{4}$ In Tönebön am See, the morning shift begins at 6.30 and ends at 14.30; the afternoon shift from 14.00 to 22.00 ; and the nightshift from 21.30 to 7.00 the next morning.

${ }^{5}$ Usually from 6.30 to $7.00,14.00$ to 14.30 , and 21.30 to 22.00 .
} 
of the norovirus, feeling faint and dehydrated from diarrhoea and vomiting. As one of the most common stomach bugs in Germany, the norovirus is highly contagious and has no specific cure. Thus many residents are bedridden and not supposed to be in contact with each other. While obviously very unpleasant, the bug usually clears up by itself in a few days. Care workers have also been ill with the virus.

Ronja $^{6}$, the charge nurse, sits in front of the computer. She has completed her day shift and frantically scrambles to make sure everything is in order. Puffs of breath race through her flaring nostrils. Too many care workers have been calling in sick, so she might not have enough workers for the coming day. Meanwhile, Martin [qualified nurse] and Bernd [care assistant] are beginning their 9.5-hour night shift. It is their fifth shift in a row. They sit around the wooden table, pour some coffee, and stretch their legs. Ronja glares at her computer monitor, then takes a deep breath and begins.

Ronja: We lack one complete morning nurse. Oh, and just so you know, you'll need to assemble these pills. This instruction comes from high up. The night shift now needs to assemble the pills.

Martin: $\quad$ Prepare and set them completely?

Ronja: Yes, it's the instruction from the boss, she even said, 'If they don't do it, I'll give them a call'. So, are you listening to me? Mr Clark's medicine needs to be assembled. Only the drugs that came this morning, they're in this case here. Mrs Green's medicine you just need to leave in the bag here, and Mrs Allen gets one more Citalopram [an antidepressant], and so does Mrs Hall. Everything is lying around here somewhere. What a mess.

\footnotetext{
${ }^{6}$ To protect their identity, I have followed the usual tradition of changing the name and defining characteristics of the
} care workers and residents. 
Martin:

Ronja:

Martin:

Ronja:

Bernd:

Ronja:

Bernd:

Ronja:

Bernd:

Ronja:

Martin:
So we have to assemble all the pills?

No, not all of them, silly. Only what I just told you. And this crap here

I don't want lying around [points to leftover drugs].

Are they all blister packed?

No, they are not. And that's all documented in the computer. Well, let's start with the handover.

Should we write it down?

Yes, that would be wise. Tomorrow morning Ruth [another qualified nurse] is here, and she hasn't been here for some time.

Oh no!

Why?

Because Ruth always wants to know everything. Ideally everything that happened in the past six weeks.

But I have already documented quite a lot. So don't worry, ok?

Yeah, you know, with the others everything is always done rather quickly, but with Ruth, oh dear. Big sister is watching.

In Tönebön am See, the handover process differed from that of a hospital. In both institutions, the meeting is an important structural component within the quality of care framework. Yet there are clear distinctions: a hospital admits patients because of accidents or diseases, with an emphasis on acute conditions. Turnover 
is high and, once treated, patients are sent on their way. The staff comprises a heterogeneous mix of team members - generally specialised and professionalised - consisting of physicians, surgeons, nurses, and care assistants. This leads to a steep hierarchical structure, centralised decision-making, and top-down communication. In a nursing home, on the other hand, the residents are frail and generally have multiple chronic illnesses. Turnover is low, as the residents stay in long-term care, mostly for the rest of their lives. The staff generally includes care workers who are less specialised than those on the hospital staff. Physicians and surgeons are not part of the team, though doctors occasionally pass in and out of the home, write or alter prescriptions, and attend to acute problems to exclude serious and potentially life-threatening conditions. This leads to a flat hierarchical structure with a broad span of control and few levels of authority. Handovers in hospitals mainly centre on patients' diagnoses, their treatment plans, and the acute diseases at hand. Many patients might be new or soon discharged. In the nursing home, in turn, all the care workers know the residents and the handover mainly centres on their states of health and mind. At the same time, the relationships between care workers tend to be more intimate. Numerous scholars have highlighted that this form of "emotional labour"- along with the accompanying "body work" (Twigg et al. 2011) - ought to be considered equivalent to physical or technical labour (Bolton 2000). At the same time, the act of caring in nursing work on many occasions hinges on managing a balancing act between presenting the detached face of a professional care worker whilst offering authentic caring behaviour (Bolton 2001). This split, Clare Stacey (2011) argues, leads care workers to forge "fictive kindships" with their patients.7

The language of the handovers is unedited and direct. The care workers know each other well - their foibles and pet peeves, how they like to spend their time, how they like to do their jobs, and what they do not enjoy. Being amongst the care workers during their handover feels like being in a circle of trust. And it is important to keep that trust nurtured and alive. In summer, shortly after my arrival, one of the care workers had called the foundation's head office to complain about the other care workers. The prevailing reaction amongst the other care workers was one of shock, outrage, and disappointment. Allegedly, the 'mole' had complained that some care workers were not doing their job, not adhering to the house rules, and not starting their

\footnotetext{
${ }^{7}$ In a similar vein, Benjamin Gray (2009) advocates that scholars studying emotional labour in health services ought to likewise include patients, relatives as well as other professions and voluntary groups in their research.
} 
shifts on time. One of the care workers was particularly upset about this breach of trust. During her cigarette break she voiced her dissatisfaction to me:

This project is just developing; many things are new. There isn't the kind of strict structure we were used to in our previous work places, so of course not everything runs smoothly in the beginning. You know, many relatives expect us to offer a rare fun programme around the clock but that isn't going to happen. We're not a circus, we have a job to do, you know. A patient's health has priority. Dear Lord, we happen to have many things on our watch, and are blamed for things beyond our control.

One of the project's initiators further highlighted how the agenda of the flexible and individual care environment could be at odds with residents' expectations:

If you have these strict times, the village is no different from a hospital, where you have certain fixed times when everyone needs to be ready. And to get rid of these rigidities is a task, and you need to talk to the relatives, who will say, 'But my mother still isn't dressed, and hasn't had her pills yet'. So there is a lot of explanatory work to be done. And that is the exhausting part. It's not the residents that are challenging but often the family members.

Indeed, a few weeks after these incidents, a resident caught a piece of meat in his throat and almost suffocated. This happened even though a carer was sitting beside him. Even though every effort was made by the care workers to clear the resident's throat, the resident had to be sent to hospital and died a few days later. He was in his early 90s. The incident had consequences, and potentially legal repercussions. Upon the resident's passing, his family called the local newspaper and a story was published about the village's negligence. The care workers felt betrayed.

\section{THE ‘AdMINISTRATIVE GAZE’}

Over the first months, the transfer of professional responsibility and accountability began to gain in urgency. From the project's initiation and through its first six months of baby steps, issues of control and 
accountability were snowballing. This seemed at odds with the promising model of a dementia village and, to make matters worse, both the home manager and the head of care soon resigned. They handed in their resignations, believing they were no longer seeing their vision realised. Issues of control surfaced frequently in the handover meetings, as seen in the excerpts above. Indeed, the village life, it seemed, became entangled in webs of control and misgiving, stemming from management, family members, and co-workers alike. While the village's residents were supposed to be able to move freely and unsupervised, the professionals were closely monitored. Carl May (1992) has argued that Foucault's notion of the clinical gaze (Foucault 1989 [1963]) lends itself very readily to interpreting questions of power and resistance in nursing work. And indeed, I would confirm that the residents were still subject to a 'clinical gaze', yet the care workers themselves were likewise caught within what I call an 'administrative gaze'. A state-of-the art touch screen computer was set up in every house. Every step of the care routine needed to be confirmed by the click of a button. Conspicuous behaviour had to be documented, and if a resident refused certain care measures, the care workers were to indicate how they convinced the resident to cooperate. Any medical information became vigilantly administered and if care workers did not file their reports by a certain time, they received a call from the main office. Meanwhile, medical hierarchy was enforced. Care workers logged into a computer system that recorded their professional qualifications. Soon, they could only access information on the residents they were allocated to in the care plan. Otherwise, anything they wrote would be considered a 'forgery', as one carer noted. 'When caring for people living with dementia, you always stand with one foot in prison', another added. A third carer lamented:

I remember the days where we only had a sheet of paper to take notes; we didn't write a care plan. When I was trained, that didn't even exist. And I dare say that the people were cared for just as well, or just as badly. All the documenting, all the writing down, the filling in forms and getting signatures, has just reached ridiculous levels. And it's the same here as in any other nursing home. I don't know, I just think if all care takers do is sitting in front of the computer, this is bringing disaster.

These administrative tasks, aided by technologically elaborate devices, affected everyone. They made some care workers more worried and more uncertain, and they ushered in an atmosphere of control, distrust, and 
irony. The administration became the watchful eye, and the increasing administrative tasks and documentation all of the sudden stood in contrast to the ideal of personal and intimate care in the village. Let us now return to the handover example to explore this development further.

Ronja clears her throat and begins the proper handover procedure, going from resident to resident.

Ronja: So Mrs Mills. OMG. She was rattled today and it was exhausting. She isn't doing well and her general health condition is bad.

Martin: What?

Bernd: $\quad$ She's dying on us.

Ronja: Yes, I think she will sometime in the near future. I'm betting on it. She even says it herself.

Martin: $\quad$ Seriously?

Ronja: Didn't you see Mrs Mills? She screams at every movement, and we don't know why.

Martin: $\quad$ Sure, but that doesn't necessarily mean that she's dying.

Ronja: Well, even her doctor said it. She had high inflammation levels in her blood and no one knows where this is coming from. I suggested that it might be a urinary tract infection, but I do not know. I'm not the doctor here. Meanwhile the doctor just stood there, and said it could well be a possible urinary tract infection, but we'd need a urine sample. So I said that we won't even start with that. Can you imagine getting a urine sample from her? 
Martin:

Ronja:

Martin:

Ronja:

Martin:

Ronja:

Bernd:

Ronja:
You'd have to insert a catheter. And listen, I'm telling you something now. It might well be a urinary tract infection; she did have some mucopurulent discharge [fluid containing mucus and pus].

That could well be the case and would also explain her inflammation values.

Most likely.

Whatever it is, she's been administered antibiotics anyway.

I will document that later.

Also, her doctor said that this was another dementia thrust, and that's why she has been going downhill. He has now changed the medication. Meanwhile her husband believes in miracles and thinks that she will come back. He doesn't listen to us at all and is against everything we suggest. We also created a drink protocol, so please do record how much she drinks every day.

But she doesn't drink little. When she drinks, she drinks properly.

Well, you just see what you can do, with the feeding cup that shouldn't be a problem. One can dress her and the other gives her something to drink. That should work. The doctor also said that if she eventually does end up not wanting to eat or drink at all, then that's the way it is. All right. So Mrs Parker rang earlier, she was confused. So I went in and asked, 'Why are you ringing, what's going on?' She replied, 'I don't know'. I then said, 'Ms. Parker, if you ring the bell once more, there will be trouble. I'm in a rage. If you're feeling ill, then you ring, but for 
everything else you do not ring anymore'. 'All right', she said. With Mrs Kelly there was nothing. Mrs Mitchell was in her room all day.

Bernd. Yes, we already said that this morning. She won't move much in the next few days I can tell you that.

Ronja: But at least today there was no vomiting and no diarrhoea. I checked up on her tonight and she didn't say anything, so all is good. Mrs Young was also in her room all day. And nothing has been documented, so everything should be fine. Mrs Price started getting sick today. And for Mrs Bennet a few drugs have been changed and she is now taking one extra Edoxaban [a blood thinner]. So there are three pills now, they will arrive from the pharmacy before Monday.

Bernd: $\quad$ Oh, that will be fun. So now we're giving her three tablets every evening when she is so used to taking her two pills [imitates resident], 'Two, two, two, two small ones'.

Ronja and Martin chuckle.

Bernd: And now there are suddenly three. She still counts well you know one, two, and three...

Ronja: Anyway, with Mrs Unruh everything is fine. Mr Shaw is on the trip that he thinks it's morning when it isn't.

Bernd: What a dad he is. I really like him. Stellar guy.

Ronja: Yeah, cuddly chap. Oh, someone also mentioned that Mrs Bell is beginning to vomit, but nothing is documented here. It figures! 
Bernd:

This morning they wanted to give her prune juice and I just barely managed to prevent this. 'Are you crazy', I said. 'We have a diarrhoea epidemic and you're handing out prune juice?' These day companions, seriously!

Ronja and Martin laugh.

Ronja: Yeah, tell me about it. Everyone is literally in the shit and they are running around with prune juice. You might as well give them an overdose of laxatives. Oh, and Mrs Bailey also vomited.

Bernd: $\quad$ Brilliant, so now the bug caught up with the Lakeside Mansion.

Ronja: $\quad$ You know, those day companions need better guidelines... and certainly a better introduction into geriatric care. I mean, seriously, they can't just run around undoing all our good work, you know.

She begins typing feverishly into the computer.

Don't mind me. I'm taking a few notes here so I know what I'll need to document later. I can't stress enough how important it is to have everything documented guys, especially since we're so few workers.

Martin and Bernd go for a smoke.

As the above excerpt illustrates, it would be a mistake to think that the primary goal of the handover was the transmission and exchange of medical and clinical data. 'In nursing homes', argues Timothy Diamond (2000 [1992]: 403), 'the work routine is defined in terms of medical tasks. This is seen most clearly in the chart, a record of each resident's care [...] [which] frames what is and is not legitimate work'. While this might well be true in part, the handover is a negotiated and imperfect process. Moreover, the work routine at Tönebön am See was not solely grounded on medical tasks. Depending on the charge nurse and the topic at hand, the tone of the handovers ranged from professional to deeply personal. The care workers talked 
about the resilience and kindness of some residents, the despair and hopelessness of others, and the potential for both vigour and frailty in them all. Furthermore, care workers went into different levels of detail, some being very brief and others spending several minutes on every resident. Keeping a record of medical and social (and at times very personal) facts formed an indispensable component of the care work. By virtue of being documented, these facts were translated into an administrative discourse - or, to apply Dorothy Smith's (1974: 257) expression, 'a documentary reality'.

On some days, particularly when admitting a new resident, the handovers would be of a more technical nature, dealing with content such as known allergies, past medical and pharmaceutical history, and social circumstances. Officially, the home's admission criteria stipulated that, in order to admit a resident, the home required an existence of dementia as diagnosed by a specialist, a presence of Parkinson's disease at an advanced stage, or an increased need for assistance due to limited everyday skills. Upon admittance, residents had to be mobile or at least able to use a wheelchair, so they could participate in the home's activities. Meanwhile, and critically, the family members had to agree with the home's care concept and accept that the care principles encourage, or even foster, the residents' active involvement in their respective household. For these criteria to be met, the management strived to hold extensive intake interviews with family members. When necessary, they requested a medical diagnosis by a specialist. They also issued a Mini Mental Status (MMS) examination to determine the resident's mental limitations and carry out an assessment of the resident's restrictions to their everyday skills and abilities. Additionally, a nutritional inventory determined the resident's nutritional status. All information was then incorporated into the care plan, which, ideally, would be recurrently updated and evaluated.

In actuality, the majority of residents showed neither an existence of dementia as diagnosed by a specialist nor a presence of Parkinson's disease at an advanced stage. ${ }^{8}$ Rather, they all displayed an increased need for assistance due to a limited ability to master everyday skills. Furthermore, the family members occasionally had a very different understanding of what constituted appropriate care for people living with dementia and

\footnotetext{
${ }^{8}$ Often, residents were admitted who did not suffer from memory loss and, in many cases, MMS examinations had never been issued. Out of 17 resident case files to which I was granted access during my fieldwork, 9 did not contain any MMS scores, 5 showed that the residents boasted an MMS score greater than or equal to 27 points (indicating normal cognition), 2 showed that the residents had a score between 18 and 23 (indicating mild cognitive impairment), and only one showed that the resident had a score under 17 (indicating severe cognitive impairment). Also see Haeusermann 2017a.
} 
seemed not particularly interested in the dementia village philosophy. One carer described this circumstance as follows:

You know, there are some family members who want their mother to get up at a certain time, be properly dressed, wearing her pearls. And I have to make sure she gets up, even if she wants to lie in. You know, that was exactly not the point of the village, right? Wasn't it the idea that people get up whenever they want, can walk around in their pyjamas and slippers if they like, and nobody cares. But of course the relatives would mind and ask why their mother is not properly dressed. Sometimes, some relatives don't seem to get the concept at all.

So whereas on some days the handovers took place under a clinical umbrella, everyday care realities and personal interactions often took centre stage. The handover became an open forum as much as a space for clarifying specific clinical issues. The excerpts of the handover show that these interpersonal practices were not marginal or occasional behaviours, but sustained and fundamental activities within the handover procedure. They shaped the role of the care workers as much as their clinical duties did. Despite the strained mood due to the lack of staff and the raging norovirus, there were lighter moments, notably when the care workers talked about the residents' personalities and their co-workers. The care workers had established an informal and occasionally bantering familiarity with each other. And often, they would complain about the 'workaday companions'.

The home differentiated between three types of care workers:

(1) The 'workaday companions' (Alltagsbegleiter), who don't engage in any medical care. They have no clinical training.

(2) The care assistants, who support the qualified nurses. Aside from giving out medication and wound treatment, they engage in all medical and physical care. They have undergone clinical training.

(3) The qualified nurses, who are in charge of medication and wound care, and hold general responsibility. They are fully qualified. 
For a short period, the three groups converged ideologically and practically, as there was an overlap in their common interest in the residents' welfare. Yet as the project continued to evolve, the relationship became more complicated. Over time, the care assistants and qualified nurses grew closer together, whereas the relations between the two and the workaday companions grew more strained. Often, it was not clear where one's scope of work ended and the others' began. A carer explained it as follows:

Well, for one there are clearly not enough care workers. The care body is not sufficient. I mean, I'm really feeling for the workaday companions. They shouldn't be cooking. They should be spending quality time with the residents, but they're just hurrying from one place to another. And worst of all, they're not properly trained at all. Ideally, there'd be a chef in every house. And the idea of having volunteers from the city helping out, come on, they have no proper training and don't know what to do with these people.

\section{'Professionalised IntimaCy'}

A one-dimensional conclusion of the above accounts could be as follows: Tönebön am See tells the tale of a once idealistic vision of a dementia village steadily deteriorating into a ceaseless cycle of accountability and control negotiations. Due to the project's fame, the home has attracted many care workers interested in a more humane, personal care environment, who want to form their care work around higher ideals. Indeed, several hundred applications from care workers are waiting to be considered in a large pile. The home's workers strive to retain their independence in the conformity-obsessed world of regulated nursing homes. They pledge never to be confined by the clinical and social conventions of dementia care. Nonetheless, they are gradually slipping into the very thing that they have escaped from - a conventional nursing home, with conventional care realities and struggles. With the manager and head of care both leaving the site, the care workers morphed into unsatisfied workers left with an unfulfilled vision. While both the care workers and the administration were initially open to integrating sociological perspectives into medical and care practice, this remained a lip service paid to the ideology but withheld from clinical practice. 
This is the one-dimensional picture, but it does not do justice to what happened in Tönebön am See. Indeed, the project evolved amongst many human and touching experiences, thankful relatives, husbands visiting their wives every day, and a strong team spirit and cohesion amongst the care workers. The home, designed to be a village in which everything resembles civic life, might not have met this vision, but it did not lack humanity. It did not lack care. The following complaint by a carer about the village's guideline to wear street clothes rather than a medical uniform exemplifies this:

Personally, I like it that we are supposed to wear colours and not run around like nurses in a hospital. But it is not very hygienic. I mean, we're supposed to be wearing our own clothes, not too much white. Well, let me tell you, I don't feel comfortable wearing my own clothes here. I've got to take them home and wash them. We have people with hepatitis $C$ here and other things, and I'm taking it all home and have to wash it separately. No one is paying me for it and I can't afford to change my clothes seven days in a row. Let me tell you, if you take some of our residents out of the hospital, they would be locked away from everyone else, no one would touch them without gloves and facemask even, but here we're just all working with them in our own clothes.

By and large, the care workers quickly found themselves between domestic intimacy and institutional detachment. As explored by James (1992), Hunter (2004), and Johnson (2015), such conflicting occupational ideologies can not only result in contradictory consequences 9 , but may in effect prove incompatible with the family care model. Indeed, during handover procedures, much like during care duties, the care workers commonly negotiated between the personal and the administrative, between empathy and professionalism. There was vivid interplay between the two worlds, a reality that I call 'professionalised intimacy'. When analysing the inner workings of the dementia village, it is impossible to create too neat a division between the personal and social (good) on the one hand, and bureaucracy and industry (evil) on the other hand. This

\footnotetext{
${ }^{9}$ In "The business of care: the moral labour of care workers", Eleanor Johnson (2015:112) found that by naturalising their emotional labour, care workers were, left "vulnerable to emotional over-involvement and client aggression". This, in turn, allowed them to "defend the moral interests of those within [their] care and to see when those interests were in conflict with the economic motivations of [their] employer".
} 
division is not always helpful and, at times, is even counterproductive. Two more recent additions to this growing literature are Laine Wiersma and Alison Pedlar's (2008) research on how a change from a longterm care setting to a summer-camp setting influences residents with dementia and Miriam Ryvicker's (2009: 12) examination of how different models of care (home vs. hospital models) shape the residents' opportunities for preserving a sense of self. While the former study highlights how a less constrained environment can positively alter relationships and lead to more equality, trust and personal interaction, the latter found that both 'home-like' and 'institutional' approaches to care can have contradictory effects on residents' sense of self. In the words of Ryvicker, her research underlines 'how a larger culture of ageism and stigma surrounding dependency can become embedded in micro-level practices and underscores the challenges of defining and implementing "good" care'. And the implications of these issues extend beyond dementia to the broader aging population as well.

The same is true for care. It simply cannot be reduced to a single meaning and purpose. It is too value-laden and multi-faceted. It is hard to say if the increasing administrative and control tasks were a begrudging slippage into a more conventional nursing home routine or if there was an ideological force behind this process. While it is conceivable that the idea of a dementia village was too much of a new-fangled vision to be realised, both the home's administration and the care workers genuinely strived to implement a cohabitation form for the residents that was not biomedically underpinned, but entirely centred on the idea of quality of life. However, due to the care workers' professional backgrounds, funding stipulation, and administrative hurdles, the form of treatment gradually slipped into more conventional nursing home care. At the same time, it is conceivable that everyone recognised from the start that merely incorporating further social dimensions into a care concept would not succeed. After all, how can one manage what are essentially neurological pathologies, without attending to them clinically?

Given the high number of actors involved, and based on my analysis, I contend that both scenarios are true. The handover procedures present a form of a bureaucratic practice; grounded in local ideas about social relationships, responsibility, and personal character (also see Herzfeld 1992). In 'The caregiving dilemma', Nancy Foner (1994) shines the spotlight on the pressures and paradoxes which nursing aides face. She offers insights into how even the best efforts to provide supportive care, wedged between emotional labour and 
bureaucratic forces, are compromised. Especially her accounts on relatives as troublemakers lend themselves to a fruitful comparison with Dutch and German care settings.

And indeed, whereas the village promoted the ideology of demedicalised and intimate care, in practice the home was subject to strict accountability structures; borrowed from hospitals and conventional nursing homes. Yet while this was not entirely a product of the care workers' frame of mind, it neither solely derived from an institutional mandate. What we see in the example of the German dementia village neither proceeded from hypocrisy nor a paradox - with the latter being a label attached to many sociological realities that seem to conflict with their underlying ideologies (see e.g. Bone 2002). Instead, we unearth conflicting agendas that are, in themselves, born out of noble ideas about care.

The dementia village shows a promise to add quality of life in a broader non-curative sense, while maintaining a quality of care that is profoundly ingrained in a curative medical approach. Both of these agendas are very real, and the care workers and the administration would endorse both.

Furthermore, it seems that the administration, by admitting residents without any cognitive impairments, undermined the rationale of a dementia village and loosened the biomedical and ideological boundary of what dementia is. Meanwhile, as can be seen in the handover examples presented, care workers in turn repeatedly asked for more professionalisation of the workaday workers. The care workers' professionalisation thus turned out to be a double-edged sword in the sense that it both elevated care workers' status and autonomy and subjugated them to rigid accountability structures. To achieve accountability and responsibility, the care workers' work thus became more structured, professionalised, timetabled, measured, administered, and controlled. Yet, was this truly an undesirable outcome? A carer put the advantage of the documentation process as follows:

The documentary reports, they provide us care workers with a legitimate reason to take breaks at times. Breaks are underestimated but important. Breaks are extremely important, you need to get out of your working environment, you can sit down, and care work in particular, can be emotionally draining.

And an administrator commented on the smoking breaks taken by so many care workers: 
Smoking at times can be seen as a legitimate reason to take breaks, and I think some people smoke even though they wouldn't necessarily want to smoke, but it gives them a break that they otherwise wouldn't get. The non-smokers then might roll their eyes, but it's still an accepted break, and non-smokers should have the same right to a break. You can't constantly be around the residents. So you go to the 'pool' or smoke. That's all you can do.

In her fine book The Person in Dementia: A Study of Nursing Home Care in the US, Athena McLean (2007: 250) draws a thought-provoking comparison between a biomedical and a communications perspective on dementia-related behavioural disturbances. She rightly concludes that "What is needed in dementia caregiving is structural and conceptual transformation through broad societal revamping of values and priorities.". In German public consciousness, care is closely tied to acute care, wherein a positive clinical outcome is desired, or even expected. The success of chronic care, however, is difficult if not impossible to measure. How does one measure success in dementia care? Indeed, care workers lack tangible results. The medicalisation of old age in a care setting, I would argue, is not only institutionally specified but also very much desired from the care workers' perspective. While dealing with cognitive decline is bound to lead to disappointment within a curative approach, caring for most physical ailments yields tangible results. So while it might be conceptually sensible to question medicine's overarching dominance, in practice, care workers' work must be guided by curative principles of health in order for care workers to feel competent as such, and, equally importantly, to not be seen as incompetent by others. The concerns among the care workers at the dementia village with regards to measuring their work efficacy were thus, in part, a product of the social context of the workplace. Meanwhile, care workers who had been trained within a medical field had the notion of curative medicine so ingrained that it appeared neither professional nor ethical for them to not focus on improving the residents' state of health. ${ }^{10}$ Decision-makers, authorities' basic training, and

\footnotetext{
${ }^{10}$ Studying the daily work in care for older people, the change of tasks and services, and the reconstruction of care as a semi-profession in Scandinavia, Annette Kamp and Helge Hvid (2012: 119) observe: 'Many of the home helpers underline their professionalism as a source of pride and as giving their work meaning. Being professional is understood as mastering the art of establishing a good relation-ship with everyone or at least most people. This relationship is a working relationship'.
} 
expertise revolve around the practice of medicine. And it is in this training - this expertise - that they put not only their professional pride, but also their faith (also see Fagerberg 2004). Thus, having care workers fulfill a mandate to provide and document curative results does not mean that they did not feel empowered by the process.

\section{CONCLUSION}

This study was conducted in the context of a growing movement away from medicalised models of care and institutionalised provision, with the care village presenting one example of efforts being made internationally to find a more humanistic and person-centred mode of support to people living with dementia. And indeed, the idea of a dementia village is compelling. The media testimonies I gathered from the Dutch care village were vivid and persuasive. It is intuitive that living in a community provides a more harmonious way to live in old age, evidenced by the significant media attention as well as conversations in gerontological and geriatric circles surrounding the opening of the care villages. Yet, through the analysis presented here we saw that despite the dementia village's pioneering vision of personalised care, with the concept grounded in reliably compelling notions of normality and community, the village came to be replete with control mechanisms. It gradually slipped from a community-inspired approach with a flat hierarchy to a more conservative, hierarchical model. Representatives of institutional authority did not lead this shift alone. My analysis lends no support to the argument that the institution overruled care workers. Instead, the institution's evolution likewise grew from the care workers' personal and professional convictions. In the Tönebön am See dementia village, there was no glamour in dementia care. The job did not leave much space for the care workers to have a sense of achievement, and no one ever won the war against dementia. As professionals, however, the care workers needed markers to define health and gain a sense of achievement. Despite longing for a more personalised and less medicalised care environment, the care workers, sometimes unconsciously and sometimes consciously, were interested in keeping the village medicalised. It is hard to acknowledge the extent to which these agendas were inherently incompatible. Without a doubt the care workers felt it was their duty to fulfil their roles as medical professionals as much as it was to enhance the residents' quality of life. All care workers had undergone dementia care training with a clear biomedical focus and the vast majority had previously been care workers in more conventional dementia or elderly care 
settings. They had developed a habitus that was institutionally compelled to achieve a certain health goal, with incentives for performing a certain form of care that placed functionality and improvement at its centre. This habitus could not easily be left at the door once they left their previous settings. Instead, it was incorporated into their professional identity in the sense of proper medical practice. Hence, institutional authority was not in direct conflict with the personal conviction of the care workers. Most importantly, the care workers wanted to be clearly differentiated from the non-professionals, who, in their eyes, often lacked the expertise to work with residents with dementia.

My concept of 'professionalised intimacy' proffers an affective model that lends itself more specifically to such care contexts. It speaks to the labour of care and the often disorientating nature of the intimacy involved in dementia care work. As various examples in the paper illustrated, policies inspired by a notion of community that were meant to make both care workers and residents more comfortable, at times had the opposite effect. Indeed, the discomfort in participating in various forms of supposedly comforting behaviour was occasionally met with a call for more professionalisation and, by extension, medicalisation of the dementia village. I hope that by outlining some of these complexities, will help foster a deeper and more critical understanding of dementia, ageing, and the care we all hope to receive in our twilight years.

\section{STATEMENT OF FUNDING}

This research received no specific grant from any funding agency in the public, commercial, or notfor-profit sectors.

\section{STATEMENT OF CONFLICT OF INTEREST}

The author declares that no competing interests exist.

\section{ACKNOWLEDGMENTS}

I would like to thank Darin Weinberg, my supervisor and mentor, for his faith in me as well as his unwavering encouragement, astute criticism, and careful guidance. I am also indebted to Jeannette Pols. I benefited from their keen intellect and scholarly acumen. Finally, my thanks go out to Sarah Franklin and Dana Rosenfeld. Every part of this paper is better from our conversations and their thoughtful comments and advice. 


\section{BIBLIOGRAPHY}

Bell, S. (1987) Changing Ideas: The Medicalization of Menopause, Social Science \& Medicine, 24, 6, 535542

Berry, L. (2013) Lessons from Abroad, Nursing Older People, 25, 6, 3

Bolton, S. (2000) Who cares? Offering emotion work as a 'gift' in the nursing labour process, Journal of Advanced Nursing, 32, 3, 580-6.

Bolton, S. (2001) Changing faces: nurses as emotional jugglers, Sociology of Heath \& Illness, 23, 1, 85-100

Bone, D. (2002) Dilemmas of emotion work in nursing under market-driven health care, International Journal of Public Sector Management, 15, 2, 140-50

Bryant, A. and Charmaz, K. (2007) The SAGE Handbook of Grounded Theory. London: SAGE.

Conrad, P. (1992) Medicalization and Social Control, Annual Review of Sociology, 18, 1, 209-232

Conrad, P. (2007) Medicalization of Society: On the Transformation of Human Conditions Into Treatable Disorders. Baltimore, MD: Johns Hopkins University Press.

Corbin, J. and Strauss, A. (1990) Grounded Theory Research: Procedures, Canons and Evaluative Criteria, Qualitative Sociology, 13, 3-21

Diamond, T. (1986) Social Policy and Everyday Life in Nursing Homes: A Critical Ethnography, Social Science \& Medicine 23,12. 1287-1295

Diamond, T. (1992) Making Gray Gold: Narratives of Nursing Home Care. Chicago: University of Chicago Press.

Diamond, T. (2000 [1992]) Nursing Homes as Trouble' In Gubrium, J.F. and Holstein, JA (eds) Aging and Everyday Life. Oxford: Blackwell Publishers. pp. 401-412

Fagerberg, I. (2004) Registered nurses' work experiences: personal accounts integrated with professional identity, Journal of Advanced Nursing, 46, 3, $284-291$.

Farmer, B.C. (1996) A Nursing Home and Its Organizational Climate: An Ethnography. London: Auburn House.

Foner, N. (1994) The Caregiving Dilemma: Work in an American Nursing Home. London: University of California Press.

Ford, J. and Sinclair, R. (1987) Sixty Years On: Women Talk About Old Age. London: Women's Press.

Foucault, M. (1989 [1963]) The Birth of the Clinic - An Archaeology of Medical Perception. Abingdon: Routledge.

Foucault, M. (2000) The Birth of Social Medicine In Faubion, J. (ed) The Essential Works of Michel Foucault. Vol. 3. New York: The New Press. pp. 134-156

Goffman, E. (1961) Asylums: Essays on the Social Situation of Mental Patients and Other Inmates. New York: Anchor Books. 
Gray, B. (2009) The Emotional labour of nursing - defining and managing emotions in nursing work, Nurse Education Today, 29, 2, 168-75.

Grün, O. (1998) Zukünftige Organisationsstrukturen für Alters- und Pflegeheime, Zeitschrift für Gerontologie und Geriatrie, 31, 6, 398-406

Gubrium, J.B. (1975) Living and Dying at Murray Manor. New York: St Martin's.

Gubrium, J.B. (1993) Speaking of Life: Horizons of Meaning for Nursing Home Residents. New York: Aldine de Gruyter.

Haeusermann, T. (2017a) The Dementias - A Review and A Call For A Disaggregated Approach, Journal of Aging Studies, 42, 22-31

Haeusermann, T. (2017b) The Dementia Village - Between Community and Society. In Krause, F. and Boldt, J (eds) Care in Healthcare. Reflections on Theory and Practice. London: Palgrave Macmillan.

Harnett, T. (2010) Seeking exemptions from nursing home routines: Residents' everyday influence attempts and institutional order, Journal of Aging Studies, 24, 4, 292-301

Herzfeld, M. (1992) The Social Production of Indifference: Exploring the Symbolic Roots of Western Bureaucracy. London: University of Chicago Press.

Hogewoning-van der Vossen, A. (2004) Living in Lifestyle Groups in Nursing Home - Changeover to a Psychosocial Model of Care-Giving in Dementia. In Jones, G.M.M. and Miesen, B.M.L. (eds) Care-Giving in Dementia: Research and Applications, 3rd ed. Hove: Brunner-Routledge. pp. 97-122

Huberman, A.M. and Miles, M.B. (1994) Data Management and Analysis Methods. In Denzin, N.K. and Lincoln, Y.S. (eds) Handbook of Qualitative Research. Thousand Oaks: SAGE. Pp. 428-444.

Hunter, B. (2004) Conflicting ideologies as a source of emotion work in midwifery, Midwifery, 20, 3, $261-$ 72

Hurley, D. (2012) 'Village of the Demented' Draws Praise As New Care Model, Neurology Today, 12, 1213

James, N. (1992) Care $=$ organisation + physical labour + emotional labour, Sociology of Health \& Illness, $14,4,488-509$.

Jenkins, C. and Smythe, A. (2013) Reflections on a Visit to a Dementia Care Village, Nursing Older People, $25,6,14-19$

Johnson, E.K. (2015) The business of care: the moral labour of care workers, Sociology of Health \& Illness, $37,1,112-126$.

Kamp, A. and Hvid, H. (2012) Elderly Care in Transition - Management, Meaning and Identity at Work. A Scandinavian Perspective Scand. Copenhagen: Copenhagen Business School Press.

Lopez, S.H. (2006). Emotional Labor and Organized Emotional Care: Conceptualizing Nursing Home Care Work, Work and Occupations, 33, 2, 133-160

May, C. (1992) Nursing work, nurses' knowledge, and the subjectification of the patient, Sociology of Health \& Illness, 14, 4, 472-487.

McAllister, C.L. and Silverman, M.A. (1999). Community Formation and Community Roles among Persons with Alzheimer's Disease: A Comparative Study of Experiences in a Residential Alzheimer's Facility and a Traditional Nursing Home, Qualitative Health Research, 9, 1, 65-85.

McLean, A. (2007) The Person in Dementia: A Study of Nursing Home Care in the US. Toronto: University of Toronto Press. 
Nye, R. (2003) The Evolution of the Concept of Medicalization in the Late Twentieth Century, Journal of the History of the Behavioral Sciences, 39, 2, 115-129t

Pols, J. (2012) Care at a Distance. Amsterdam: Amsterdam University Press.

Ryvicker, M. (2009) Preservation of Self in the Nursing Home: Contradictory Practices Within Two Models of Care, Journal of Aging Studies, 23,1, 12-23

Smith, D.E. (1974) The Social Construction of Documentary Reality, Sociological Inquiry, 44, 4, 257-268

Stacey, C.L. (2011) The Caring Self: The Work Experiences of Home Care Aids. Cornell: Cornell University Press.

Thornberg, R. and Charmaz, K. (2014) Grounded Theory and Theoretical Coding. In Flick, U. (ed) The SAGE Handbook of Qualitative Data Analysis. London: Sage. pp. 153-169

Turner, B. (1995) Medical Power and Social Knowledge. $2^{\text {nd }}$ ed. London: Sage.

Twigg, J. et al. (2011) Conceptualising body work in health and social care, Sociology of Health \& Illness $33,2,171-188$

Wiersma, E.C. and Pedlar, A. (2008) The Nature of Relationships in Alternative Dementia Care Environments, Canadian Journal on Aging / La Revue canadienne du vieillissement, 27,1, 101-108

Zola, I.K. (1972) Medicine as an Institution of Social Control, The Sociological Review, 20, 487-504 